CORRECTION

\title{
Correction to: Large-scale protein level comparison of Deltaproteobacteria reveals cohesive metabolic groups
}

Marguerite V. Langwig (1D), Valerie De Anda (1), Nina Dombrowski (1), Kiley W. Seitz, lan M. Rambo, Chris Greening (D), Andreas P. Teske (iD) and Brett J. Baker (i)

(C) The Author(s), under exclusive licence to International Society for Microbial Ecology 2021

The ISME Journal (2022) 16:899; https://doi.org/10.1038/s41396-021-01091-w

Correction to: The ISME Journal https://doi.org/10.1038/s41396021-01057-y

Following the publication of this article, the authors noted an error in Figure 6 in the box labelled C, SAR324-the reaction in the top left is incorrect and was mislabelled N2O oxidation. The reaction has been corrected and the label changed to $\mathrm{N} 2 \mathrm{O}$ reduction.

The original article has been corrected.

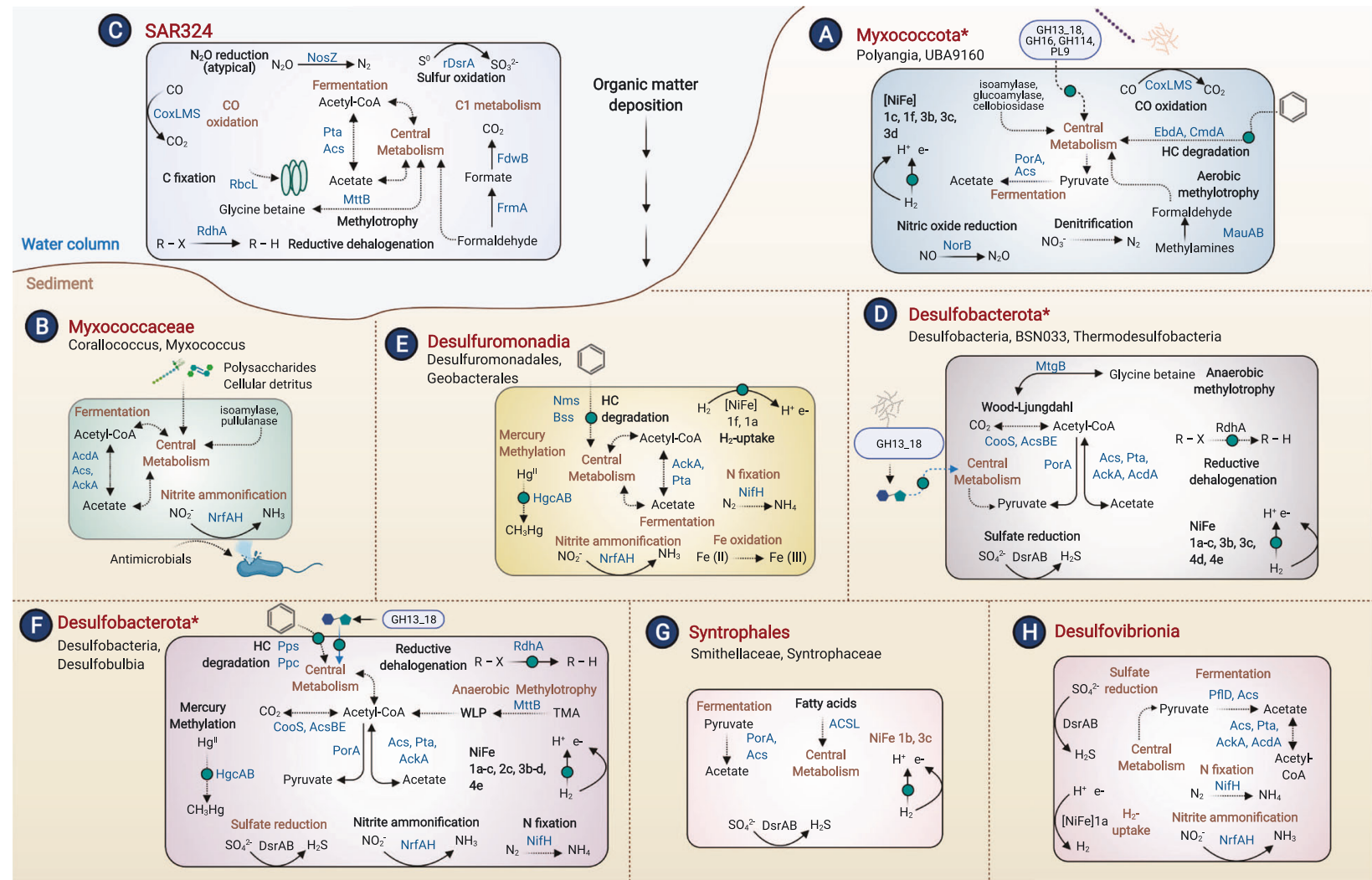

Fig. 6 